\title{
An Empirical Approach to Analysing the Demographic Consequences of Seed Dispersal by Frugivores
}

\author{
H. Godínez-Alvarez and P. Jordano
}

\section{Introduction}

Seed dispersal is a key stage in the life cycle of plants because it contributes to the recruitment of new individuals (Howe and Smallwood, 1982). Many authors have suggested that seed dispersal has important demographic consequences, and as such it is necessary to link comprehensive analyses of seed dispersal with studies of plant demography in order to completely understand the population dynamics of plants (Schupp and Fuentes, 1995; Godínez-Alvarez et al., 2002; Jordano and Godoy, 2002; Wang and Smith, 2002; Howe and Miriti, 2004). In this chapter, we present an approach for integrating these two disparate types of study as a way to better understand the effects of seed dispersal on the population growth rate of plants.

Dispersal of seeds by fruit-eating animals is a complex process whose consequences encompass a series of concatenated stages beyond fruit consumption and seed removal, such as seed deposition, germination, and seedling emergence and establishment (Jordano and Herrera, 1995; Wang and Smith, 2002). Perhaps due to this complexity, no study to date has analysed all these sequential stages and determined their consequences by means of an explicitly demographic approach. Since successful seed dispersal by animals is the outcome of a mutualistic interaction between the animals and the plants, it is expected that it has net positive effects on the populations of each participating species. The effects of seed dispersal should ideally be observed and measured in the population growth rates of both animals and plants (Addicott, 1986), which requires an understanding of frugivory and the behaviour of frugivores beyond fruit removal.

The effects of seed dispersal have traditionally been incorporated into plant demographic studies by means of simulations with population dynamics models that are often built without considering the detailed 
natural history of the particular plant-frugivore system being examined (Horvitz and Schemske, 1995; Martinez-Ramos and Alvarez-Buylla, 1995; Valverde and Silvertown, 1997). On the other hand, incorporating the consequences of mutualistic interactions into matrix population models has so far had only limited success (Herrera and Jordano, 1981; Horvitz and Schemske, 1994; Godínez-Alvarez et al., 2002). A particular limitation to the viable integration of seed dispersal with its demographic consequences has been an inability to link the effects of frugivores' actions with their delayed consequences at later stages of recruitment.

To accomplish our goal in this chapter, we first review some existing approaches to the study of seed dispersal. We then present a brief discussion of the population projection matrix models which are commonly used in plant demographic studies. Finally, we use empirical data to illustrate our ideas and then discuss the possible benefits and disadvantages of our approach. We argue that matrix population models can incorporate the necessary elements of analysis to clearly integrate the effects of frugivore activity on plant population dynamics. Ultimately, we hope to stimulate more integrated ecological studies, thus contributing to our understanding of the key role of seed dispersal in plant demography.

\section{Approaches to the Study of Seed Dispersal}

From a theoretical perspective, in order to understand the demographic consequences of seed dispersal, it is essential to obtain data on all critical stages and ecological processes from the reproduction of the parent plants through to reproductive maturity of the new adults (Schupp and Fuentes, 1995). Relevant data include fruit production, the composition of the frugivore assemblage and the quantity of seeds removed by each species, frugivore effects on seed germination, the microsites into which frugivores deposit seeds, and the effects of those microsites on seed survival, germination and adult recruitment.

Because the evaluation of such broad-ranging data types is methodologically so complex, studies of seed dispersal to date have only analysed certain stages of the overall process. Some studies have concentrated on the pre-dissemination stage, mainly through an analysis of the quantities of seeds dispersed by different frugivore species (Schupp, 1993; Jordano and Schupp, 2000), whereas others have focused on the post-dissemination stage, generally by estimating seedling recruitment probabilities (Jordano and Herrera, 1995; Rey and Alcántara, 2000; García, 2001; Traveset et al., 2003).

The overall consequence of seed dispersal can perhaps be viewed best within the framework of 'disperser effectiveness'. Disperser effectiveness is defined as the relative contribution of a frugivore species to plant reproduction, which depends on the quantity of seeds removed and the quality of treatment given to the seeds during the process of dispersal (Schupp, 1993). At present, no single study has thoroughly analysed both 
the quantitative and qualitative components for all the frugivores of a particular plant species, but very good beginnings have been made for some systems (Howe, 1977; Herrera and Jordano, 1981; Murray, 1988; Reid, 1989; Jordano and Schupp, 2000). The frequency of visits and the number of seeds removed per visit are among the best-documented quantitative aspects, while fruit handling, post-feeding movement patterns of frugivores, and the effects of handling on seed germination are some of the best-studied qualitative aspects (see Table 17.1 for examples).

Studies addressing recruitment probabilities are generally based on the analysis of seed and seedling survival in different microhabitats where seed rain may or may not have been adequately quantified. Important microhabitat-specific data include the number of seeds dispersed to that site by the frugivore community as a whole, the proportion of seeds suffering predation, the proportion of seeds germinating, and at least some minimal data on survival of the seedlings. Actual data on seedling survival has been extremely variable in duration, ranging from several months up to 4 years post-germination (Table 17.1). Based on such data, recruitment probabilities for particular plant species have been calculated as the product of the transition probabilities among the early life cycle stages (e.g. ovule to seedling, Traveset et al., 2003; seed to seedling, Herrera et al., 1994; Jordano and Herrera, 1995; Rey and Alcántara, 2000). In many cases at least, the processes acting during these stages of the life cycle are independent and the eventual outcomes are site-specific (Jordano and Herrera, 1995; Schupp, 1995) and often context-dependent in other ways (see Schupp, Chapter 20, this volume).

In order to determine the role of frugivores in plant population dynamics, we believe that it is necessary to improve our knowledge of the pre- and post-dissemination stages of seed dispersal and then to identify the methodological limitations for integrating frugivore activity with the success of seeds and seedlings following handling and dissemination. A review of the relevant literature showed that for some species the postdissemination stage has been intensively studied while data regarding the pre-dissemination stage are scarce or non-existent, and vice versa (Table 17.1). Thus, an imbalance is evident between the amount of data for the pre- and post-dissemination stages of a given species.

In addition, even if we have adequate data we are limited in our ability to effectively link these stages. Effectively linking such data is essential in order to integrate seed dispersal with information on plant demography. We suggest this integration may be achieved through the use of projection matrices, which incorporate data on survival, growth and fecundity of individuals at different stages of the life cycle, and summarize it in relevant population parameters such as the population growth rate, or lambda $(\lambda$; Caswell, 2001). In particular, we suggest that one way to better understand the impact of frugivores on the demography of plant populations is to use projection matrices to link the pre- and post-dissemination stages for each individual disperser species. 
Table 17.1. A sample of studies that have assessed aspects of the quantitative and qualitative components of disperser effectiveness, sensu Schupp (1993). Numbers indicate distinct aspects of the quantitative or qualitative components of disperser effectiveness: 1 = Relative abundance, expressed mainly as number of individuals per hour of observation; $2=$ Frequency of visits to the plant, estimated as the number of visits per hour; $3=$ Time spent feeding on the plant; $4=$ Number or proportion of seeds and/or fruits removed per dropping, cache or visit; 5 = Post-foraging behaviour, expressed as direction of movements, time between movements, movement distance, and/or number of movements to distinct landscape perches, units or microhabitats; $6=$ Number or proportion of seeds defecated per minute; $7=$ Number or proportion of seeds germinating after gut passage and/or germination rate; $\mathbf{8}=$ Number or proportion of seeds and/or seedlings in different microhabitats;

$9=$ Number or proportion of seedlings surviving for $1-4$ years; $-=$ Not evaluated.

\begin{tabular}{|c|c|c|c|}
\hline Plants/Animals & Quantity & Quality & Reference \\
\hline $\begin{array}{l}\text { Casearia corymbosa } \\
\text { (Flacourtiaceae)/Birds (6 spp.) }\end{array}$ & $1,2,4$ & 7,8 & Howe, 1977 \\
\hline $\begin{array}{l}\text { Prunus mahaleb (Rosaceae) } \\
\text { Birds ( }>10 \mathrm{spp} \text {.) }\end{array}$ & $1,2,3,4$ & 5,8 & $\begin{array}{l}\text { Herrera and Jordano, 1981; } \\
\text { Jordano and Schupp, } 2000\end{array}$ \\
\hline Plants (3 spp.)/Birds (6 spp.) & 1 & 6,7 & Murray, 1988 \\
\hline $\begin{array}{l}\text { Amyema quandang } \\
\quad \text { (Loranthaceae)/Birds (2 spp.) }\end{array}$ & 4 & 7,8 & Reid, 1989 \\
\hline Pinus jeffreyi (Pinaceae)/Rodents (2 spp.) & 4 & 8 & Vander Wall, 1993 \\
\hline Juniperus ashei (Cupressaceae)/Birds (2 spp.) & 3,4 & 5,8 & Chávez-Ramírez and Slack, 1994 \\
\hline Maesa lanceolata (Maecaceae)/Birds (2 spp.) & 2,4 & 6,7 & Graham et al., 1995 \\
\hline Phillyrea latifolia (Oleaceae)/Birds & 4 & $7,8,9$ & Jordano and Herrera, 1995 \\
\hline Plants (6 spp.)/Frugivores & 4 & 7,9 & Chapman and Chapman, 1996 \\
\hline $\begin{array}{l}\text { Phoradendron californicum } \\
\text { (Viscaceae)/Birds ( } 3 \text { spp.) }\end{array}$ & 1,2 & - & Larson, 1996 \\
\hline Plants (2 spp.)/Rodents (2 spp.) & - & 8,9 & Forget, 1997 \\
\hline Plants (6 spp.)/Birds (3 spp.) & 3,4 & 5,6 & Sun et al., 1997 \\
\hline Ocotea endresiana (Lauraceae)/Birds (5 spp.) & - & 5,8 & Wenny and Levey, 1998 \\
\hline Plants (4 spp.)/Birds (6 spp.) & 4 & 8 & Loiselle and Blake, 1999 \\
\hline Plants (9 spp.)/Birds (2 spp.) & - & 5,6 & Holbrook and Smith, 2000 \\
\hline Olea europaea (Oleaceae)/Birds & 4 & $7,8,9$ & Rey and Alcántara, 2000 \\
\hline Plants (18 spp.)/Lagothrix lagothricha (Atelidae) & 4 & 5,7 & Stevenson, 2000 \\
\hline $\begin{array}{l}\text { Beilschmiedia pendula (Lauraceae)/ } \\
\text { Birds (4 spp.) }\end{array}$ & - & $7,8,9$ & Wenny, 2000a \\
\hline Ocotea endresiana/Birds (5 spp.) & - & $7,8,9$ & Wenny, 2000b \\
\hline \multicolumn{4}{|l|}{ Juniperus communis } \\
\hline (Cupressaceae)/Birds (2 spp.) & 4 & $7,8,9$ & García, 2001 \\
\hline \multicolumn{4}{|l|}{ Corema album (Empetraceae)/ } \\
\hline Birds (2 spp.), Rodents (1 spp.) & - & $7,8,9$ & Calviño-Cancela, 2002, 2004 \\
\hline Ruppia maritima (Ruppiaceae)/Birds (9 spp.) & 4 & 7 & Figuerola et al., 2002 \\
\hline $\begin{array}{l}\text { Neobuxbaumia tetetzo (Cactaceae) } \\
\text { /Bats (1 spp.), Birds (4 spp.) }\end{array}$ & 1,2 & 5,7 & Godínez-Alvarez et al., 2002 \\
\hline Plants (12 spp.)/Monkeys (3 spp.) & 2,4 & 8 & Kaplin and Lambert, 2002 \\
\hline \multicolumn{4}{|l|}{ Leptonychia usambarensis } \\
\hline (Sterculiaceae)/Birds (11 spp.) & 4 & 9 & Cordeiro and Howe, 2003 \\
\hline \multicolumn{4}{|l|}{ Rhamnus ludovici-salvatoris } \\
\hline (Rhamnaceae)/Birds (2 spp.) & 4 & 8,9 & Traveset et al., 2003 \\
\hline Pinus monophylla (Pinaceae)/Rodents (6 spp.) & 4 & 8 & Hollander and Vander Wall, 2004 \\
\hline
\end{tabular}




\section{Population Projection Matrices and Seed Dispersal}

Projection matrix models are commonly used in the study of plant demography because they provide basic population parameters such as population growth rates, stable size distributions, and reproductive values (Caswell, 2001). Projection matrices used in the study of plants generally use size or life cycle stage for categorizing the population structure (Fig. 17.1a) because these are generally better predictors than age of plant fate. The structure can be depicted with life cycle diagrams in which different stages of the life cycle are represented by $n_{i}$, where $n$ is the number of individuals in stage $i$, along with the probability that an individual in stage $i$ at time $t$ contributes through survival, growth, or reproduction to stage $j$ at time $t+1$. Based on these diagrams, projection matrices are easily derived by considering the links between the different stages as well as their associated transition probabilities (Fig. 17.1b).

The entries in a projection matrix can vary depending on the complexity of the life cycle (Silvertown et al., 1993; Caswell, 2001). For instance, projection matrices for species with relatively simple life cycles in which individuals at one stage can only either grow to the next stage or

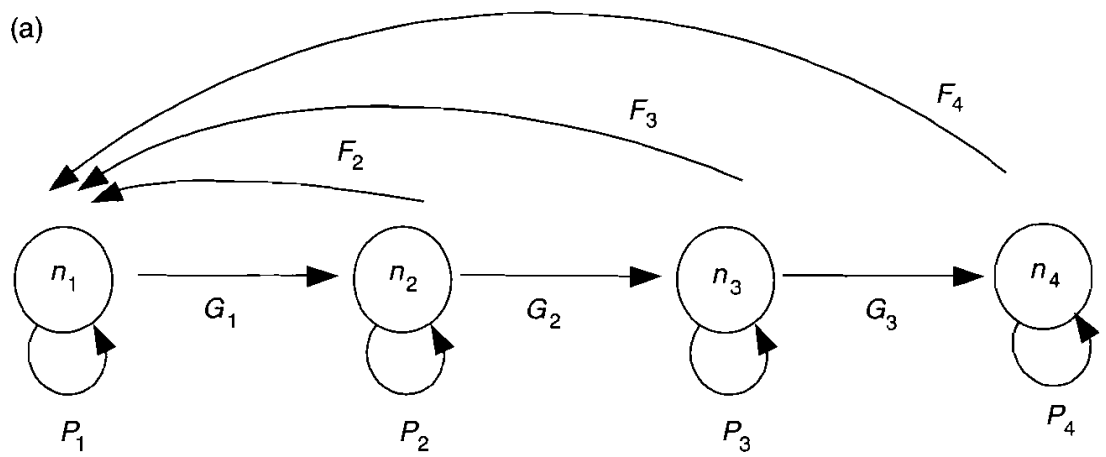

(b)

$$
A=\left[\begin{array}{cccc}
P_{1} & F_{2} & F_{3} & F_{4} \\
G_{1} & P_{2} & 0 & 0 \\
0 & G_{2} & P_{3} & 0 \\
0 & 0 & G_{3} & P_{4}
\end{array}\right]
$$

Fig. 17.1. An example of a life cycle diagram (a) and its corresponding projection matrix (b) for a plant with a relatively simple life cycle categorized in four stages $\left(n_{i}\right)$. Individuals in stage $i$ can survive and grow $\left(G_{i}\right)$ into the next stage, or survive and remain in the same stage $\left(P_{f}\right)$, during a given time interval. Individuals in the last three stages contribute to the first stage through sexual reproduction $\left(F_{i}\right)$. 
survive at the same stage during a specified time interval, and in which adults can only reproduce sexually, will only have possible values along the main diagonal, the first lower subdiagonal, and the first row (see Fig. 17.1b). Values along the main diagonal refer to the survival probabilities of individuals that do not grow to the next stage, those in the first subdiagonal represent the transition or growth probabilities, and those in the first row indicate fecundities.

The fecundity value of a given adult stage can be calculated as the product of the probability of reproduction for that stage, the mean number of seeds produced by a reproductive individual of that stage, and the probability of a seed becoming a seedling during the time-step, which is considered constant for all adult stages (Godínez-Alvarez et al., 1999; Box 17.1). Frugivore effects may be incorporated by considering data on quantitative (i.e. frequency of visits to the plants and seed removal) and qualitative (i.e. seed germination after gut passage and number of flights to different landscape patches) aspects of each species of frugivore. The first step is to calculate:

1. The probability of seed removal;

2. The probability of seed germination after gut passage;

3. The probability that seeds would be delivered to each distinct patch type;

4. The probability of making the transition from seed to seedling in each distinct patch type.

Using these probabilities, new fecundity values can be estimated, which in turn may be incorporated in the projection matrix to calculate the population growth rate due to frugivore effects (see Box 17.1 for a detailed description about how to calculate and integrate these four probabilities into fecundity values).

With this approach we can begin to evaluate the effects of frugivores on plant demography. Depending on the system, we can do this for each individual species of frugivore separately or for disperser functional groups composed of species sharing some taxonomical or ecological affinities (see Dennis and Westcott, Chapter 9, this volume). Either way, we can use fairly easily collected data to estimate, respectively, the contribution of particular species or of functional groups to population growth rate (see Box 17.2). In addition, we can use this approach to evaluate, among other things, the consequences for plants of an avian seed predator or of an invasive disperser species, as well as the population collapse or even extinction of a given species of frugivore. By estimating the population growth rate under various scenarios (e.g. with and without a particular frugivore) we can determine the relative importance of given species to the maintenance of plant populations.

\section{Dispersal of Neobuxbaumia tetetzo Seeds: an Example}

In this section we present a brief overview of seed dispersal of the columnar cactus Neobuxbaumia tetetzo (Cactaceae) as an example of the ideas 


\section{Box 17,1 incorporating frugivore effects into the fecundity values of matrix models}

Frugivere effects can be incorporated into the fecundity values of matrix models through the estimation of four probabilities.

1. The probability of seed removal:

2. The probability of seed germination after gut passage;

3. The probability of delivering seeds to particular patches;

4. The probability of making the transition from seed to seedling in each patch.

To Illustrate the estimations of these probabilities, consider an example with three species of trugivores (,$B$ and G) for which we have data on the frequency of visits to the plants and the number of seeds removed per visit

To estimate the probability of seed removal, these data are first multiplied together and then this product is summed across all species. From this total, the relative proportion of total seeds removed by each species of frugivore is calculated, this represents the probability of seed renoval per species.

\begin{tabular}{|c|c|c|c|c|}
\hline $\begin{array}{l}\text { rrugivore } \\
\text { species }\end{array}$ & $\begin{array}{l}\text { Frequency } \\
\text { of visits (1) }\end{array}$ & $\begin{array}{l}\text { No of seeds } \\
\text { removed }(2)\end{array}$ & $\begin{array}{l}\text { Product of } \\
1 \text { and } 2\end{array}$ & $\begin{array}{l}\text { Relative } \\
\text { proportion }\end{array}$ \\
\hline$B$ & 3 & $\begin{array}{r}50 \\
5 \\
100 \\
\text { Total }\end{array}$ & $\begin{array}{r}150 \\
35 \\
500 \\
685\end{array}$ & $\begin{array}{l}0.05 \\
0.73 \\
1.00\end{array}$ \\
\hline
\end{tabular}

Other aspects of seed dispersal such as fruit handing success (e.g. proportion of fruits ingested and successfully removed away from the parent tree relative to the number of fruils handled) can easily be incorporated into this approach.

The probability of seed germination after gut passage can be estimated with laboratory experiments using seeds defecated by each species of trugivore. The mean proportion of seeds germinating for each species of frugivore may be interpreted as the probability of seed germination after gut passage.

To estimate the probability of delivering seeds to particular patches, one can determine the number of postfeeding llights to different landscape patches for each species of frugivore and then calculate the relative proportion of total flights to a microhabitat type that are made by each species. A hypothetical example with three species of rugivores and wo patches is:

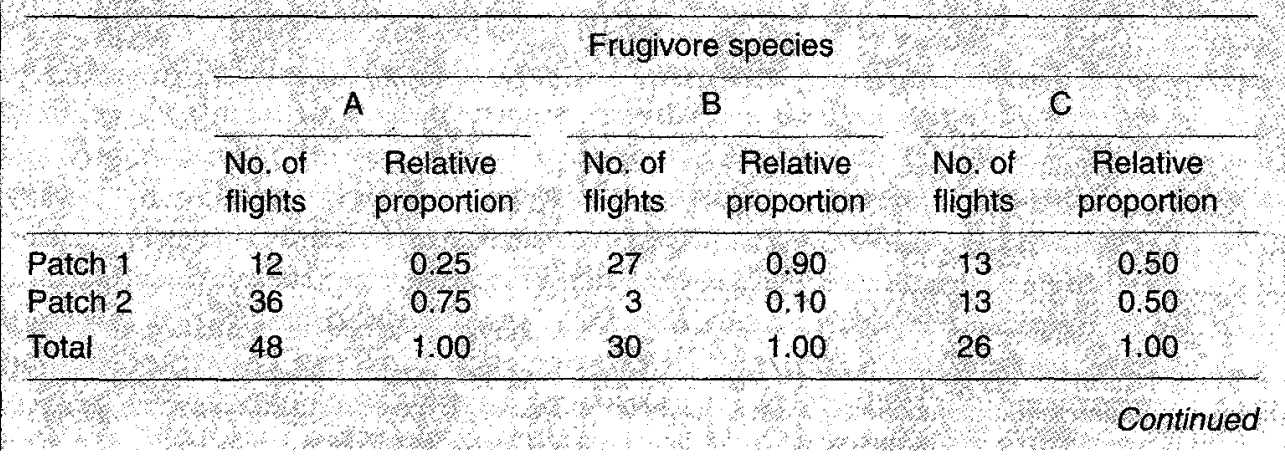




\section{Box 17.1 Continued}

These probabilities can be combined with the frequency of visits to the plants and the number of seeds removed per visit to estimate the number of seeds in a patch type contributed by a given species.

The probability of making the transition from seed to seeding in each patch can be estimated through field experiments in those patch types considered relevant in each of these patches, seeds directly obtained from fruits can be sown hi the field to determine the number of emerging seedlings as Well as the number of surviving seedings after 1 year. The mean proportion of surviving seedlings with respect to the total number of seeds sown may be considered as the probability that seeds germinate and survive in each patch.

To incorporate these probabilities into the fecundity values, first consider that the fecundity based on the recruitment of 1 year old seedings can be calculated as:

$$
F=0.8
$$

where $F$ is the fecundity tor individuals in stage, $F$ is the probability of reproduction. $S$ is the mean number of seeds produced per individual, and $C$ is the probability of passing from seed to seedling in the field after I year. which is constant for all adult stages. Based on this definition, C can be replaced in (1) by the four estimated probabilities above. That is:

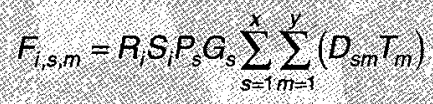

where. $F$, $R$, and $S$, are the same as in $(1), P$, is the probability of seed removal by the frugivore $s, G_{s}$ is the probability of seed germination after gut passage. $D_{s n}$ is the probability that seeds would be delivered in the patch $m$ by $s$, and $T_{m}$ is the probability of making the transition from seed to seedling in $\mathrm{m}$. The simplest case is when plants are visited only by one rugivore species (s - 1 ) and their seeds and seedlings successfully germinate and survive ony in one patch type $(m=1)$. n this case, $P_{5}, G_{5}$, and $D_{s}$ are The probabilities estimated for the only species of frugivore and $T_{m}$ is constant. When there is more than one trugivore species $(s=x)$ and patch type $(m=1)$, $P$. can be calculated as the sum of the removal probabilities estimated for each species, and $G_{s}$ as the mean weighted by the seed removal probability

presented above. Detailed information on this plant and its seed dispersers can be found in Godínez-Alvarez et al. (2002).

Neobuxbaumia tetetzo is a common plant in the Tehuacán Valley, a dry zone in south-central México. Fleshy fruits produced on branch tips dehisce at night, exposing a whitish, sugary pulp with hundreds of small black seeds. Fruits are consumed at night by the long-nosed bat Leptonycteris curasoae (Phyllostomatidae) and during the day by several species of birds such as cactus wren (Campylorhynchus brunneicapillus; Troglodytidae), curved-billed thrasher (Toxostoma curvirostre; Mimidae) and grey-breasted woodpecker (Melanerpes hypopolius; Picidae). Since the traits of $N$. tetetzo fruits agree with those suggested for fruits consumed by bats (van der Pijl, 1982), it is reasonable to assume that bats have a greater contribution to cactus population growth rate than birds do. 


\section{Box 172. Disperser functional groups, combining the probabilities of frugivore species with ecological or taxonomical affinities}

The probabilities calculated for each species of frugivore can be used individually or in combination with other species that share some ecological or taxonomical affinities in order to evaluate the species specific or functional group effects of frugivores on population growth rate.

Consider for simplicity that probabilities of seed removal $(P$ ), seed germination after gut bassage (G), and seed deposition $\left(D_{s m}\right)$ in two particular landscape patches have been calculated for two species of birds (A and B) and one species of bat $(9)$. The probabilities of making the transition from seed to seeding $\left(T_{\mathrm{m}}\right)$ in each patch were calculated independent of the frugivore species and remain constant. As an example:

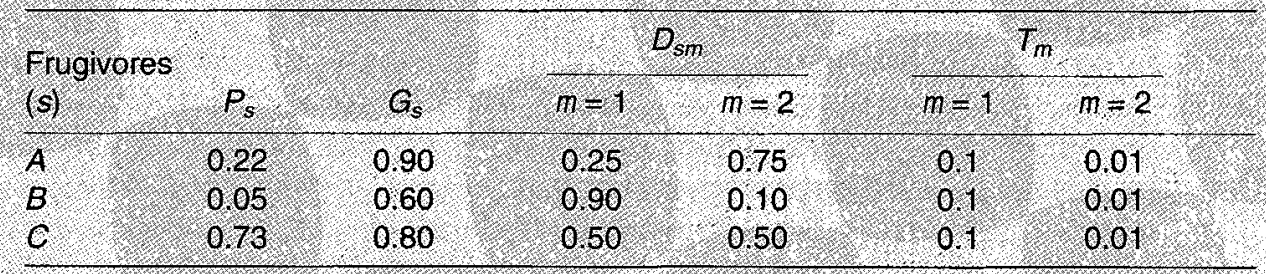

Based on these data and Eqh (2). it is possible to estinate, for example, the effects of birds $(A+B)$, bats $(C)$, and all rugivore species $(A+B+C)$. in the cases of birds and all frugivore species, the probability of seed removal can be calculated as the sum of the probabilities estimated for each species being considered $(A+B$ or $4+B+C$, while the probabily of seed germination can be estimated as the mean weighted by the seed removal probability.

\begin{tabular}{|c|c|c|c|}
\hline $\begin{array}{l}\text { Frugivores } \\
\text { species }\end{array}$ & $P_{s}$ & & $\left.\sum_{s=1}^{x} \sum_{1}\left(D_{s i n}\right)_{m}\right)$ \\
\hline$A$ & 0.22 & 0.90 & 0.0325 \\
\hline$B$ & 0.05 & 0.60 & 0.091 \\
\hline$A+B$ & 027 & 0.84 & 0.1235 \\
\hline$C^{\prime}$ & 0.73 & 0.80 & 0,055 \\
\hline$A+B+C$ & 1.00 & 0.81 & 0.7785 \\
\hline
\end{tabular}

These probabilities may be substituted in the calculation of the fecundities, to obtain new values that integrate the effects of bats, of birds, or of all rugivore species.

To test this assumption, information on seed dispersal for different frugivores was incorporated into a population projection matrix of $N$. tetetzo (Godínez-Alvarez et al., 1999). This projection matrix was built by grouping individuals in size categories based on the height of the principal trunk and then by considering survival, reproduction and growth probabilities of individuals in each category over a 1 -year interval. Size categories were: adling $1(<2 \mathrm{~cm})$, seedling $2(2-8 \mathrm{~cm})$, seedling $3(8-15 \mathrm{~cm})$, sapling 
$(15-45 \mathrm{~cm})$, juvenile $(45-100 \mathrm{~cm})$, immature $(100-150 \mathrm{~cm})$, mature 1 $(150-250 \mathrm{~cm})$, mature $2(250-350 \mathrm{~cm})$, mature $3(350-450 \mathrm{~cm})$, mature 4 $(450-550 \mathrm{~cm})$, mature $5(550-650 \mathrm{~cm})$ and mature $6(>650 \mathrm{~cm})$, yielding a total of 12 categories. The projection matrix only has values in the main diagonal (survival without growth probabilities), the first lower subdiagonal (growth probabilities), and the first row (fecundity values). Fecundity values were estimated as the product of: (i) the probability of reproduction; and (ii) the mean number of seeds produced by a reproducing individual for each reproductive category, as well as (iii) the constant estimated probability of passing from seed to seedling over a 1-year time-step (Fig. 17.2).

The seed dispersal data included quantitative and qualitative aspects of disperser effectiveness (Schupp, 1993). The quantitative aspects were frequency of visits to plants (visits/h) and seed removal by each species (number of seeds removed/fruit). This latter aspect was estimated as number of seeds removed per fruit, instead of per visit, because of the large number of seeds and their small size. The qualitative aspects were the proportion of seed germination after gut passage and the number of postfeeding flights to trees and shrubs for each species of frugivore, and the number of surviving seedlings beneath trees and shrubs after 1 year. The number of post-feeding flights and the number of surviving seedlings were estimated only for trees and shrubs, since these plants provide the only microsites suitable for seed germination and seedling establishment (Godínez-Alvarez et al., 1999). Using these data, an estimate of: (i) the probability of seed removal; (ii) the probability of seed germination after gut passage; (iii) the probability of delivering seeds to tree and shrub microsites; and (iv) the probability of making the transition from a seed to a seedling beneath trees and shrubs, were calculated for each species of

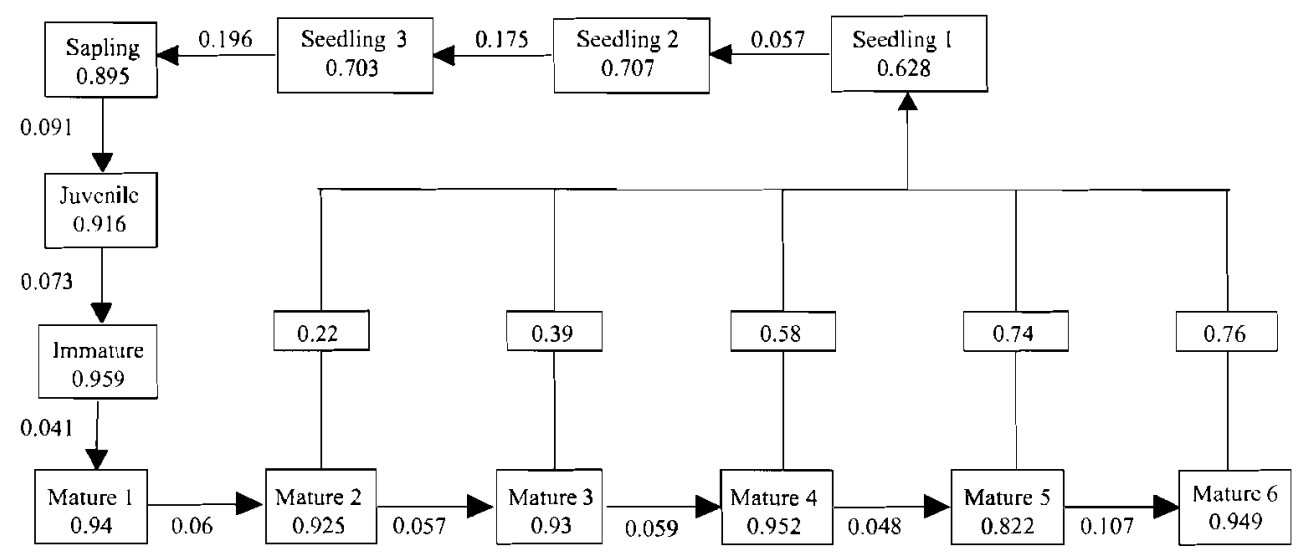

Fig. 17.2. Life cycle diagram of the columnar cactus Neobuxbaumia tetetzo. Values inside boxes refer to survival probabilities $\left(P_{i}\right.$ values in Fig. 17.1a) and arrows represent transition or growth probabilities $\left(G_{i}\right.$ values in Fig. 17.1a). Boxes above mature categories 2-6 indicate fecundity values $\left(F_{i}\right.$ values in Fig. 17.1a). 
frugivore, and were used to modify the fecundity values of the $N$. tetetzo matrix model. The calculation of these probabilities and the modification of the fecundity values were made following the procedures described in Box 17.1 .

The role of different frugivores on the population dynamics of $N$. tetetzo was determined through matrix simulations assessing the effects of individual species as well as the effect of all dispersers acting together. The effect of a species of frugivore was simulated by incorporating the fecundity values calculated for that species into the matrix model. To simulate the effect of all dispersers acting together, the probability of seed removal was calculated as the sum of all the probabilities estimated for each species, whereas the probability of seed germination was estimated as the mean weighted by the seed removal probability (see Box 17.2). The population growth rate (lambda, $\lambda$ ) was calculated for each simulation by multiplying the projection matrix by a vector representing the number of individuals in each size category. This procedure was repeated with each resulting vector until its proportions remained constant, at which point the population grows at a rate equal to lambda.

Results showed that species of frugivore differed in their effects on the population dynamics of $N$. tetetzo (Table 17.2). As expected, the estimated population growth rate due to the long-nosed bat, $L$. curasoae, was higher than those estimated to be due to the birds $C$. brunneicapillus, M. hypopolius and $T$. curvirostre. The higher contribution of $L$. curasoae was mostly due to its higher probabilities of seed removal and of delivering seeds to tree and shrub microsites. The matrix simulations conducted for all species of frugivores acting together also showed a high contribution to the population growth rate of this columnar cactus (Table 17.2).

\section{Conclusions and Perspectives}

Many authors have pointed out that in order to advance our understanding of seed dispersal by frugivores it is essential to evaluate the demographic consequences of dispersal for plant populations (Schupp and Fuentes, 1995; Godínez-Alvarez et al., 2002; Jordano and Godoy, 2002; Wang and Smith, 2002; Howe and Miriti, 2004). To accomplish this goal, it is necessary to obtain detailed information on the outcome of frugivore activity and their potential effects on critical stages of the life cycle of plants, such as seed germination and seedling, juvenile and adult survival and growth - the delayed consequences of dispersal. The studies conducted up until now have provided some information on the dispersal effectiveness of frugivores and the demographic fate of seeds and seedlings. However, this information has not allowed an evaluation of the demographic consequences of seed dispersal because it is incomplete for most plants and because the methodological approaches needed to integrate this information into plant demography have not been clearly described. The importance of this chapter is the demonstration that an empirical approach based on 
Table 17.2. Frugivore effects empioyed to modify the projection matrix of Neobuxbaumia tetetzo. Effects were estimated according to Eqn (2) in Box 17.1, where $P_{s}=$ probability of seed removal by species $s, G_{s}=$ probability of seed germination after gut passage, $D_{s m}=$ probability of delivering seeds in the patch $m$ by $s$, and $T_{m}=$ probability of making the transition from seed to seedling in $m$.

\begin{tabular}{|c|c|c|c|c|c|c|}
\hline Frugivore species & $P_{s}$ & $G_{s}$ & $D_{s m}$ & $T_{m}$ & $\sum_{s=1}^{x} \sum_{m=1}^{y}\left(D_{s m} T_{m}\right)$ & $\begin{array}{c}\text { Estimated } \\
\text { rate of } \\
\text { increase }\end{array}$ \\
\hline Leptonycteris curasoae (bat) & 0.987 & 0.86 & 0.72 & 0.00139 & 0.001 & 1.003 \\
\hline $\begin{array}{l}\text { Campylorhynchus } \\
\text { brunneicapillus (bird) }\end{array}$ & 0.002 & 0.98 & 0.43 & 0.00139 & $6.0 \times 10^{-4}$ & 0.97 \\
\hline Melanerpes hypopolius (bird) & 0.008 & 0.96 & 0.03 & 0.00139 & $4.2 \times 10^{-5}$ & 0.97 \\
\hline Toxostoma curvirostre (bird) & 0.003 & 0.98 & 0.12 & 0.00139 & $1.7 \times 10^{-4}$ & 0.97 \\
\hline All frugivores & 1.000 & 0.86 & - & - & $1.8 \times 10^{-3}$ & 1.009 \\
\hline
\end{tabular}

$P_{s}$ is estimated as the product of the frequency of visits and number of seeds removed per fruit for each frugivore; this product was summed across all frugivores, and the relative proportion of the total was calculated for each species. For all frugivores, it was calculated as the sum of the removal probabilities estimated for each species.

$G_{s}$ is estimated as the mean proportion of germinated seeds in laboratory experiments using seeds defecated by each frugivore species. For all frugivore species, it was estimated as the mean weighted by the seed removal probability.

$D_{s m}$ is estimated as the proportion of post-feeding flights to trees and shrubs out of the total number of flights recorded.

$T_{m}$ is calculated as the mean proportion of seedlings surviving under trees and shrubs after 1 year.

projection matrices allows us to explore the ecological consequences of seed dispersal in an explicitly demographic context. This approach is based on the incorporation of frugivore effects into the matrix elements concerned with plant reproduction in order to simulate frugivore impacts on the population growth rate of plants. This allows a comprehensive analysis of the effectiveness of different frugivore species or guilds with the best measure possible: their effects on plant population dynamics.

Since this approach may enhance our understanding of seed dispersal, it is essential to conduct more studies using these ideas in order to determine their validity and applicability. In this context, it is important to define those aspects of seed dispersal that provide the minimum information needed to conduct these demographic evaluations. Generally, the basic data needed are:

1. The frequency of visits by a species of frugivore to plants;

2. The number of seeds dispersed per visit;

3. The species-specific effects on seed germination;

4. The species-specific contribution to seed rain in distinct and relevant microhabitats;

5. Data on seed and seedling survival in these microhabitats. 
Item 4 requires a simultaneous assessment of seed rain, frugivore foraging and habitat preferences at the landscape level (e.g. Wenny and Levey, 1998; Jordano and Schupp, 2000). With this information, it is possible to estimate the probabilities to be incorporated into the first row of a projection matrix. Other aspects such as the reliability of frugivores, digestive physiology, and post-foraging behaviour, among others, may also be incorporated into the calculation of these probabilities, but much of these data may be most important for dissecting why species differ in effectiveness, rather than for actually quantifying differences.

The likelihood of seeds being dispersed to sites where seedling recruitment can successfully occur in the field may be significantly altered by spatio-temporal variability, such as landscape heterogeneity and annual changes in the frugivore community (Jordano and Herrera, 1995; Schupp, 1995; Schupp and Fuentes, 1995; Herrera, 1998; Howe and Miriti, 2004). In addition, the 'quality' of a given type of dispersal site (e.g. microhabitat) may change temporally and spatially (see Schupp, Chapter 20, this volume). Thus, in order to completely understand the demographic consequences of seed dispersal, it would be important to also begin to quantify variability in critical factors and to evaluate the effects of such variability on the population growth rate of plants. These evaluations are especially important, since spatial and temporal variability can affect not only the estimates of the frugivore effects, but also the estimates of the other matrix elements, influencing the rate of population growth and the contribution of different life stages to this rate (i.e. elasticities; see Pfister, 1998). The approach described here may be used as a preliminary basis to incorporate these factors, through monitoring annual changes in plant demography as well as in some selected stages of seed dispersal. Such monitoring also might include different habitats where it is known that some demographic processes such as recruitment or survival probabilities may change throughout the life cycle of plants (Howe and Miriti, 2004). Based on this information, it is possible to build multi-annual matrices for different habitats, which integrate frugivore effects and plant demography. Comparing the population growth rates and elasticities calculated for each of these matrices would permit an evaluation of the extent to which the relative importance of particular species of frugivores and different life stages to plant population dynamics changes among habitats and/or years.

The approach discussed here depends on the availability of projection matrices to estimate the growth rate of populations. These matrix models have assumptions that might limit the use of the proposed approach under some conditions (Caswell, 2001).

- Projection matrices are time-invariant in that survival and growth probabilities and fecundity values of individuals remain constant through time.

- They also assume that populations grow at a constant rate until reaching a stable distribution; thus they do not consider densitydependent effects. 
- In addition, there are potential problems associated with multiplying demographic estimates (e.g. fecundity of individuals in a size class) that have variances.

Because of these assumptions, the proposed approach should be used only to generate scenarios of the possible effects of frugivores on the population growth rate, instead of trying to predict the actual population dynamics of plants (Godínez-Alvarez et al., 2002). Such explorations are extremely valuable in and of themselves; indeed, the patterns are more valuable than the actual values.

The relative impacts of survival, growth and fecundity on the growth rate of populations apparently change depending on the life history of plants (Silvertown et al., 1993). In general, fecundity is the most important demographic process for the population persistence of plants with short life cycles, whereas adult survival is the process with the highest contribution for long-lived perennials. Due to these differences, it is possible that frugivore effects on the population growth rate would be more easily detected in plants with short life cycles than in long-lived perennials, since evaluations are based on the modification of the fecundity values. However, field evidence is needed to support these ideas.

An understanding of the demographic consequences of seed dispersal by frugivores depends upon the integration of information on frugivore activities and plant demography. With the approach discussed here, we hope to stimulate more integrative studies that contribute to a better understanding of the ecological consequences of this biological interaction.

\section{Acknowledgements}

We thank Eugene W. Schupp and two anonymous reviewers for their critical comments on the manuscript. This chapter was written during H.G.A.'s research stay at the Integrative Ecology Group, Estación Biológica de Doñana. The financial support for this stay was provided by the Dirección General de Asuntos del Personal Académico, UNAM.

\section{References}

Addicott, J.F. (1986) On the population consequences of mutualism. In: Diamond, J. and Case, T.J. (eds) Community Ecology. Harper and Row, New York, pp. 425-436.

Calviño-Cancela, M. (2002) Spatial patterns of seed dispersal and seedling recruitment in Corema album (Empetraceae): the importance of unspecialized dispersers for regeneration. Journal of Ecology 90, 775-784.

Calviño-Cancela, M. (2004) Ingestion and dispersal: direct and indirect effects of frugivores on seed viability and germination of Corema album (Empetraceae). Acta Oecologica 26, 55-64.

Caswell, H. (2001) Matrix Population Models: Construction, Analysis, and Interpretation, 2nd edn. Sinauer Associates, Sunderland, Massachusetts. 
Chapman, C.A. and Chapman, L.J. (1996) Frugivory and the fate of dispersed and nondispersed seeds of six African tree species. Journal of Tropical Ecology 12, 491-504.

Chávez-Ramírez, F. and Slack, R.D. (1994) Effects of avian foraging and post-foraging behavior on seed dispersal patterns of Ashe juniper. Oikos 71, 40-46.

Cordeiro, N.J. and Howe, H.F. (2003) Forest fragmentation severs mutualism between seed dispersers and an endemic African tree. Proceedings of the National Academy of Sciences USA 100, 14052-14056.

Figuerola, J., Green, A.J. and Santamaria, L. (2002) Comparative dispersal effectiveness of wigeongrass seeds by waterfowl wintering in south-west Spain: quantitative and qualitative aspects. Journal of Ecology 90, 989-1001.

Forget, P.-M. (1997) Effect of microhabitat on seed fate and seedling performance in two rodentdispersed tree species in rain forest in French Guiana. Journal of Ecology 85, 693-703.

Garcia, D. (2001) Effects of seed dispersal on Juniperus communis recruitment on a Mediterranean mountain. Journal of Vegetation Science 12, 839-848.

Godínez-Alvarez, H., Valiente-Banuet, A. and Valiente, B.L. (1999) Biotic interactions and the population dynamics of the long-lived columnar cactus Neobuxbaumia tetetzo in the Tehuacan Valley, Mexico. Canadian Journal of Botany 77, 203-208.

Godínez-Alvarez, H., Valiente-Banuet, A. and Rojas-Martínez, A. (2002) The role of seed dispersers in the population dynamics of the columnar cactus Neobuxbaumia tetetzo. Ecology 83, 2617-2629.

Graham, C.H., Moermond, T.C., Kristensen, K.A. and Mvukiyumwami, J. (1995) Seed dispersal effectiveness by two bulbuls on Maesa lanceolata, an African montane forest tree. Biotropica 27, 479-486.

Herrera, C.M. (1998) Long-term dynamics of Mediterranean frugivorous birds and fleshy fruits: a 12-year study. Ecological Monographs 68, 511-538.

Herrera, C.M. and Jordano, P. (1981) Prunus mahaleb and birds: the high efficiency seed dispersal system of a temperate fruiting tree. Ecological Monographs 51, 203-218.

Herrera, C.M., Jordano, P., López-Soria, L. and Amat, J.A. (1994) Recruitment of a mastfruiting, bird-dispersed tree: bridging frugivore activity and seedling establishment. Ecological Monographs 64, 315-344.

Holbrook, K.M. and Smith, T.B. (2000) Seed dispersal and movement patterns in two species of Ceratogymna hornbills in a West African tropical lowland forest. Oecologia 125, 249-257.

Hollander, J.L. and Vander Wall, S.B. (2004) Effectiveness of six species of rodents as dispersers of singleleaf piñon pine (Pinus monophylla). Oecologia 138, 57-65.

Horvitz, C.C. and Schemske, D.W. (1994) Effects of dispersers, gaps, and predators on dormancy and seedling emergence in a tropical herb. Ecology 75, 1949-1958.

Horvitz, C.C. and Schemske, D.W. (1995) Spatiotemporal variation in demographic transitions of a tropical understory herb: projection matrix analysis. Ecological Monographs 65, 155-192.

Howe, H.F. (1977) Bird activity and seed dispersal of a tropical wet forest tree. Ecology 58, 539-550.

Howe, H.F. and Miriti, M.N. (2004) When seed dispersal matters. BioScience 54, 651-660.

Howe, H.F. and Smallwood, J. (1982) Ecology of seed dispersal. Annual Review of Ecology and Systematics 13, 201-228.

Jordano, P. and Godoy, J.A. (2002) Frugivore-generated seed shadows: a landscape view of demographic and genetic effects. In: Levey, D.J., Silva, W.R. and Galetti, M. (eds) Seed Dispersal and Frugivory: Ecology, Evolution and Conservation. CAB International, Wallingford, UK, pp. 305-321.

Jordano, P. and Herrera, C.M. (1995) Shuffling the offspring: uncoupling and spatial discordance of multiple stages in vertebrate seed dispersal. Écoscience 2, 230-237.

Jordano, P. and Schupp, E.W. (2000) Seed dispersal effectiveness: the quantity component and patterns of seed rain for Prunus mahaleb. Ecological Monographs 70, 591-615. 
Kaplin, B.A. and Lambert, J.E. (2002) Effectiveness of seed dispersal by Cercopithecus monkeys: implications for seed input into degraded areas. In: Levey, D.J., Silva, W.R. and Galetti, M. (eds) Seed Dispersal and Frugivory: Ecology, Evolution and Conservation. CAB International, Wallingford, UK, pp. 351-364.

Larson, D.L. (1996) Seed dispersal by specialist versus generalist foragers: the plant's perspective. Oikos 76, 113-120.

Loiselle, B.A. and Blake, J.G. (1999) Dispersal of melastome seeds by fruit-eating birds of tropical forest understory. Ecology 80, 330-336.

Martínez-Ramos, M. and Alvarez-Buylla, E.R. (1995) Seed dispersal and patch dynamics in tropical rainforests: a demographic approach. Écoscience 2, 223-229.

Murray, K.G. (1988) Avian seed dispersal of three neotropical gap-dependent plants. Ecological Monographs 58, 271-298.

Pfister, C.A. (1998) Patterns of variance in stage-structured populations: evolutionary predictions and ecological implications. Proceedings of the National Academy of Sciences USA 95, 213-218.

Reid, N. (1989) Dispersal of mistletoes by honeyeaters and flowerpeckers: components of seed dispersal quality. Ecology 70, 137-145.

Rey, P.J. and Alcántara, J.M. (2000) Recruitment dynamics of a fleshy-fruited plant (Olea europaea): connecting patterns of seed dispersal to seedling establishment. Journal of Ecology 88, 622-633.

Schupp, E.W. (1993) Quantity, quality, and the effectiveness of seed dispersal by animals. In: Fleming, T.H. and Estrada, A. (eds) Frugivory and Seed Dispersal: Ecological and Evolutionary Aspects. Kluwer Academic, Dordrecht, The Netherlands, pp. 15-29.

Schupp, E.W. (1995) Seed-seedling conflicts, habitat choice, and patterns of plant recruitment. American Journal of Botany 82, 399-409.

Schupp, E.W. and Fuentes, M. (1995) Spatial patterns of seed dispersal and the unification of plant population ecology. Ecoscience 2, 267-275.

Silvertown, J., Franco, M., Pisanty, I. and Mendoza, A. (1993) Comparative plant demography: relative importance of life cycle components to the finite rate of increase in woody and herbaceous perennials. Journal of Ecology 81, 465-476.

Stevenson, P.R. (2000) Seed dispersal by woolly monkeys (Lagothrix lagothricha) at Tinigua National Park, Colombia: dispersal distance, germination, and dispersal quantity. American Journal of Primatology 50, 275-289.

Sun, C., Ives, A.R., Kraeuter, H.J. and Moermond, T.C. (1997) Effectiveness of three turacos as seed dispersers in a tropical montane forest. Oecologia 112, 94-103.

Traveset, A., Gulias, J., Riera, N. and Mus, M. (2003) Transition probabilities from pollination to establishment in a rare dioecious shrub species (Rhamnus ludovici-salvatoris) in two habitats. Journal of Ecology 91, 427-437.

Valverde, T. and Silvertown, J. (1997) An integrated model of demography, patch dynamics and seed dispersal in a woodland herb, Primula vulgaris. Oikos 80, 67-77.

van der Pijl, L. (1982) Principles of Dispersal in Higher Plants. Springer, Berlin, Germany.

Vander Wall, S.B. (1993) Cache site selection by chipmunks (Tamias spp.) and its influence on the effectiveness of seed dispersal in Jeffrey pine (Pinus jeffreyi). Oecologia 96, 246-252.

Wang, B.C. and Smith, T.B. (2002) Closing the seed dispersal loop. Trends in Ecology and Evolution 17, 379-385.

Wenny, D.G. (2000a) Seed dispersal of a high quality fruit by specialized frugivores: high quality dispersal? Biotropica 32, 327-337.

Wenny, D.G. (2000b) Seed dispersal, seed predation, and seedling recruitment of a neotropical montane tree. Ecological Monographs 70, 331-351.

Wenny, D.G. and Levey, D.J. (1998) Directed seed dispersal by bellbirds in a tropical cloud forest. Proceedings of the National Academy of Sciences USA 95, 6204-6207. 